\title{
Entre o discurso e a prática: implementação do currículo de História no programa educacional São Paulo faz escola
}

Between speech and practice: the implementation of History curriculum in educational program são Paulo faz escola

Ana Paula Giavara* Iraíde Marques de Freitas Barreiro ${ }^{\star *}$

\section{Resumo}

No âmbito do programa educacional São Paulo faz escola (2008-2012), este artigo oferece ao leitor uma visão crítica acerca do processo de proposição e implementação do currículo de História em duas escolas públicas do interior paulista. Partindo da reforma curricular paulista da década de 1980, busca delinear uma trajetória para as discussões acerca do ensino de História na contemporaneidade. Para tanto, utiliza documentos da reestruturação curricular elaborados pela Secretaria da Educação estadual, depoimentos dos sujeitos educacionais, bem como observações do cotidiano escolar. Partilha da perspectiva cultural de análise da escola, que confere autenticidade às ações de seus sujeitos e interroga como professores de História e gestores escolares participaram do processo de elaboração e implementação do referido currículo.

Palavras-chave: reforma curricular; ensino de História; São Paulo faz escola.

\section{Abstract}

In the ambit of educational program São Paulo faz escola (2008-2012), this article offers a critical view of the proposal and implementation of History curriculum in two different schools at São Paulo countryside. It starts with the curricular remodeling occurred in the 80 's and intents to chart a path for discussions involving modern History teaching. In order to achieve this goal, this article uses documents from the curricular restructuration made by the State Department of Education, testimonies of educational subjects and observations of school's daily routine. It shares the cultural perspective of school analysis, which gives authenticity to the actions of its subjects and it inquiries how History teachers and school administrators participated in the elaboration and implementation of said curriculum.

Keywords: curricular reform; History teaching; São Paulo faz escola.

\footnotetext{
* Doutoranda, Programa de Pós-Graduação em Educação, Universidade Estadual Paulista (Unesp). Faculdade de Filosofia e Ciências de Marília (SP). anagiavara@hotmail.com

** Professora Doutora, Universidade Estadual Paulista (Unesp), Faculdade de Ciências e Letras de Assis, Departamento de Educação.iraide@assis.unesp.br
} 
A formulação e a implementação de propostas curriculares para a disciplina de História sempre se configuraram como objeto de acirrados debates ao longo da história educacional brasileira. Os problemas residem, sobretudo, nas disputas entre os sujeitos do sistema educacional (professores, intelectuais e poder governamental) pela produção dos currículos, na seleção de seus conteúdos e concepções e na implantação das matrizes curriculares na escola. Ao longo dos anos 1980, tais dificuldades estiveram ligadas à falta de consenso entre os agentes elaboradores do currículo e às disputas políticas no interior da própria Secretaria, com repercussões no processo de planejamento e execução da Proposta Curricular de História dirigida pela Coordenadoria de Estudos e Normas Pedagógicas (Cenp), no âmbito da Secretaria da Educação do Estado de São Paulo (SEE-SP).

Nova iniciativa de reforma curricular foi empreendida pela SEE-SP e está em vigor desde 2008, expressa pelo programa educacional São Paulo faz escola. Entre outros aspectos, suas ações são direcionadas à uniformização educacional, o que incluiu a formulação de propostas curriculares e materiais didáticos padronizados para todas as disciplinas do ensino fundamental II e ensino médio da rede pública paulista de ensino.

Nesse contexto, este artigo objetiva oferecer ao leitor uma visão crítica do processo de elaboração e implementação do currículo de História, com base na investigação desenvolvida em duas escolas públicas no interior paulista, em que se explicitam as contradições e dificuldades desse processo. Serão discutidas as relações existentes entre as intencionalidades curriculares do São Paulo faz escola e as experiências vivenciadas pelos sujeitos (professores de História e gestores) durante a reforma, no que se refere tanto ao processo de elaboração dos currículos e de seus materiais didáticos, quanto às ações da SEE-SP na sua implantação.

Este artigo é recorte de uma investigação mais ampla desenvolvida no mestrado, ${ }^{1}$ cujo objetivo foi analisar, por meio de um estudo de caso, o processo de implantação e manutenção da proposta curricular de História para o ensino médio em duas escolas estaduais no interior paulista, no período de 2008 a 2012. Verificou-se como a SEE-SP subsidiou os professores e os gestores para o trabalho com a nova matriz curricular. Buscou-se também analisar como e em que medida as orientações curriculares foram postas em prática pelos professores de História em suas aulas. 
Para o estudo de caso que fomenta este artigo foram realizadas entrevistas com os sujeitos educacionais (professores de História e gestores), observações do cotidiano escolar e análises de documentos, referentes à Proposta Curricular de 2008 e ao Currículo de 2010, bem como de resoluções pertinentes ao assunto. A análise dos dados coletados atendeu às proposições de uma análise qualitativa, a qual permitiu extrair da situação investigada dados que não poderiam ser observados mediante a adoção de apenas um procedimento de coleta. Desse modo, foram efetuados "exames cruzados" sobre as informações colhidas, o que possibilitou relativizá-las, questioná-las e validá-las ou não. Sarmento define esse tipo de análise como "triangulação", a qual "operacionaliza-se no acto metodológico que visa esclarecer um determinado facto, acontecimento ou interpretação, a partir de três (ou mais) fontes, três tipos de dados ou três métodos diferentes" (Sarmento, 2003, p.157).

Valendo-se da perspectiva "cultural" de análise, a escola foi compreendida primeiramente como subordinada ao seu caráter institucional de regulação social, historicamente constituído a partir da escolarização dos saberes elementares na Idade Moderna, o que lhe confere características comuns a outras instituições de mesma natureza. Existe, contudo, um processo de combinação, um "amálgama”, em que esta natureza comum é influenciada pela prática dos sujeitos escolares, o que atribui à instituição identidades particulares. Logo, as ações de cada unidade, embora regidas por orientações únicas, podem ser distintas, pois não há garantias de que as normas preceituadas nos documentos (de reforma, por exemplo) serão cumpridas tal qual foram propostas, uma vez que cada escola e cada sujeito processam de modo particular o entendimento e a apropriação das diretrizes (Silva Junior, 2004, p.55).

Em consonância com a consideração da "cultura escolar" estão os autores da historiografia francesa tais como André Chervel (1991), Jean-Claude Forquin (1993) e Dominique Julia (2001), os quais, por intermédio da História das Disciplinas Escolares, reforçam o caráter eminentemente criativo e autônomo das instituições de ensino. Trata-se da capacidade que a escola possui para edificar uma cultura particular mediante a "confecção" de seus produtos, como as disciplinas, por exemplo. Desse modo, são negados neste artigo os esquemas explicativos que compreendem a escola como receptáculo de saberes externos, bem como seus sujeitos (professores, gestores e alunos) como 
passivos nas relações de ensino-aprendizagem ou nos processos de reforma educacional.

Desta perspectiva teórica de análise, a prática escolar foi analisada tendo em vista a reforma curricular em curso, pois é no interior das salas de aulas que melhor se verifica o destino tomado pelas políticas públicas educacionais. Em concordância com as disposições trazidas pela discussão circunscrita ao conceito de "cultura escolar", compreende-se que a implementação do currículo de História pode ter tomado rumos diferentes nas mais de 5 mil escolas da rede pública de ensino do estado de São Paulo, obedecendo à cultura de cada Diretoria de Ensino, de cada escola e de cada sala de aula.

\section{O Currículo de História da Cenp nos anos 1980: PONTO DE PARTIDA}

O processo de seleção cultural dos saberes históricos revela as transformações que a sociedade atravessa ao longo do tempo, dada a relação de reciprocidade entre os desígnios das disciplinas escolares e os anseios sociais. Nesse sentido, “a manutenção de uma disciplina escolar no currículo deve-se à articulação com os grandes objetivos da sociedade" (Bittencourt, 1998, p.17). Por sua vez, os processos de reforma curricular consideram, além de questões próprias do universo escolar, também as intenções traçadas externamente, pois "as transformações substantivas de uma disciplina escolar ocorrem quando suas finalidades mudam. As finalidades mudam para atender um público escolar diferenciado e como resposta às suas necessidades sociais e culturais" (ibidem, p.17).

De acordo com tal perspectiva, as constantes disputas que cercearam a elaboração dos currículos de História ao longo da trajetória educacional brasileira são, na contemporaneidade, elucidativas da relevância do debate que antecede a elaboração das matrizes curriculares para essa disciplina. Assim, para analisar a atual reforma curricular de História, é importante recuperar a dinâmica de proposição e implementação do currículo de História elaborado pela Cenp no estado de São Paulo, que se estendeu de meados da década de 1980 até início dos anos 1990, pois se identifica a existência de um processo de rupturas e permanências entre ambos os movimentos. 
Durante o auge do regime ditatorial brasileiro - de 1964 até a segunda metade da década de 1970 -, em benefício da manutenção do sistema político vigente, intelectuais, professores e a sociedade como um todo estiveram alijados da participação política nas questões nacionais. Nesse contexto, as Ciências Humanas e a disciplina de História, acadêmica ou escolar, foram compreendidas pelo Estado autoritário como possíveis veículos de difusão de ideias contrárias às suas ações.

Procurando controlar as disciplinas e o trabalho docente, o estado de São Paulo criou guias curriculares. Com intuito de direcionar a aprendizagem na rede pública de ensino, os cadernos verdes da disciplina de Estudos Sociais, popularmente chamados "Verdão", serviam aos princípios da manipulação estatal, impedindo que a reflexão e a crítica fizessem parte do currículo escolar. Houve naquele contexto "uma tentativa de legitimar, pelo controle do ensino de História, a lógica política do Estado e da classe dominante, anulando a liberdade de formação e de pensamento da juventude, homogeneizando a imagem destes sujeitos sociais, em torno da imagem do Homem que melhor serve aos interesses do Estado e da Nação" (Fonseca, 2006, p.61).

Nessa conjuntura, os profissionais da educação eram vistos como os executores das diretrizes do Estado, não participando da elaboração das reformas, tampouco da constituição dos currículos. A eles cabia a tarefa de reproduzir o conhecimento preconizado pelos órgãos de segurança nacional, cuja atuação buscava intervir nos movimentos sociais e nas instituições de ensino, fazendo que os sujeitos educacionais fossem desapropriados da função criadora. Os conteúdos curriculares e as estratégias metodológicas passaram a ser definidos por especialistas, alheios ao processo de ensino-aprendizagem.

A utilização do termo "guia curricular" em detrimento de "proposta curricular" na década de 1970 aponta para a manipulação por parte do Estado militar sobre a prática pedagógica. Assim, o "guia" apresenta-se como "um documento diretor que deveria ser seguido". Ao contrário, o termo "proposta" traz como "princípio fundamental a possibilidade de ser seguida ou não, por se tratar de uma proposta, uma sugestão (Martins, 1996).

Contudo, já em fins da década de 1970, a ação de grupos sociais contrários às ações militares contribuiu para que o aparelho estatal se desgastasse e, paulatinamente, propiciou a abertura necessária para que a sociedade pudesse novamente inserir-se nos debates públicos. Nesse contexto, as discussões 
educacionais, além de terem sido retomadas, ganharam papel determinante na reivindicação social por mudanças estruturais na forma política. De maneira geral, recusava-se a visão da escola e do ensino de História como ferramentas de manutenção do regime e como reprodutores do conhecimento conveniente apenas às classes dominantes (Cordeiro, 2000).

As iniciativas de reformulação do ensino de História eram de cunho individual e coletivo e partiram de professores de História que formulavam projetos didáticos alternativos, das universidades que ofereciam contribuições provenientes dos mais recentes estudos historiográficos e educacionais e do próprio Estado que, pressionado pelas reivindicações sociais por mudanças, passou a divulgar propostas curriculares mais pertinentes à nova organização política nacional. Também participavam das discussões associações científicas como a Associação Nacional de História (Anpuh) e a mídia, representada, principalmente, pela imprensa escrita.

Desse modo, iniciou-se um processo de revisão das legislações concernentes ao ensino de História. Muitas Secretarias da Educação estaduais e municipais iniciaram projetos de reforma curricular, inclusive a SEE-SP que, em 1983, por meio da Cenp, empreendeu uma revisão nas grades disciplinares das Ciências Humanas. Com auxílio de professores de História da rede pública, a equipe técnica da Cenp iniciou a construção de um currículo para os $1^{\circ}$ e $2^{\circ}$ graus de ensino. Após muitas discussões entre intelectuais da Cenp, professores de História da rede, associações sindicais, mídia e universidades paulistas, foram elaboradas cinco versões do documento curricular, cuja versão final foi distribuída em 1992 às escolas do estado de São Paulo (Martins, 1996).

A nova forma de elaborar o currículo, com auxílio dos professores da rede, apontou para uma das principais inovações trazidas pelo debate que envolveu a implementação da nova matriz curricular de História da Cenp: a perspectiva de 1970 que compreendia o professor como executor das propostas do Estado é substituída pelo seu entendimento como um sujeito participativo no processo de elaboração dos currículos e das reformas.

Desse modo, o estado de São Paulo, por intermédio da Cenp, buscou atender à demanda de democratização do ensino clamada por professores e intelectuais que, no novo regime democrático, eram eleitores. Assim, os novos currículos não poderiam ser arbitrariamente prescritos pela SEE-SP, ao contrário, e para não enfrentar um processo de desmoralização nos novos tempos 
democráticos, o estado procurou o consenso entre os grupos participantes do processo de reforma educacional e curricular.

Contudo, os professores da rede de ensino e os acadêmicos que auxiliavam na construção da proposta dividiam-se por questões de posicionamento político e teórico. Não havia consenso nem mesmo entre os intelectuais que compunham a equipe técnica da Cenp. Tal fato fez que, entre os anos de 1986 e 1992, fossem lançadas cinco versões do documento curricular de História, cada uma delas representando os interesses dos grupos de intelectuais elaboradores, os quais, por sua vez, reproduziam os conflitos que se processavam na sociedade de maneira mais ampla.

As dificuldades de implementação de um currículo de História tinham assim um viés político e eram decorrentes das alternâncias dos coordenadores da Cenp pelos secretários da Educação em exercício. Essas mudanças dificultavam a elaboração dos currículos, já que a substituição do secretário representava também a mudança dos coordenadores e das equipes que formulavam as matrizes curriculares. Com a alteração na chefia da coordenação, os projetos em andamento ganhavam novos rumos ou até mesmo novos graus de importância (Martins, 1998).

No momento em que João Cardoso Palma Filho coordenou a Cenp, as 1, $2^{\mathrm{a}} \mathrm{e} 3^{\mathrm{a}}$ versões do documento curricular apresentadas à rede, entre os anos de 1986 e 1988, representaram de fato a inovação a que se propunha o ensino de História paulista, ou seja, promover de maneira democrática a ampla participação do professorado na elaboração das reformas de ensino. Contudo, durante o período em que a Cenp foi coordenada por Teresa Roserley Neubauer da Silva (Rose Neubauer), as $4^{\mathrm{a}}$ e $5^{\mathrm{a}}$ versões do currículo de História, constituídas entre os anos de 1991 e 1992, foram assinadas por intelectuais das universidades paulistas sem a participação dos professores da rede. Tais propostas não se apresentaram como uma continuação das três versões anteriores do currículo, e a 5a de 1992, nem mesmo contou com a equipe técnica de História da Cenp, órgão que passava por um processo de esvaziamento de funções, burocratização e perda do poder decisório (Martins, 1996).

Por influência do processo de descentralização educacional iniciado nos anos 1990 por Rose Neubauer, a Cenp perdeu seu poder de decisão na elaboração dos currículos, transformando-se novamente em um órgão administrativo e burocrático, cuja função era a normatização curricular. Desviando o 
olhar dos professores para outras questões em voga na época, as bandeiras da participação social e da democratização dos currículos, hasteadas por professores, intelectuais e pela própria Cenp na segunda metade dos anos 1980, foram recolhidas.

Essa atuação da SEE-SP no início dos anos 1990 inseriu-se em um movimento de "contrarreforma conservadora" impulsionado pela permanência de grupos conservadores, remanescentes do período ditatorial, no poder. Tais grupos agiam por força de interesses clientelistas e levaram ao retrocesso não somente o campo educacional, mas outras esferas sociais. Nesse período, os caminhos estiveram abertos para que os princípios neoliberais adentrassem os poderes Legislativo e Executivo nacionais. $\mathrm{O}$ auge desse processo remonta ao governo presidencial de Fernando Collor de Mello, considerado o amálgama de forças conservadoras com o consenso neoliberal (Fagnani, 1996).

Mesmo que a proposta de História implementada pela Cenp em 1992 tenha deixado para trás parte das inovações preconizadas nos anos 1980, o debate educacional promovido naquele contexto de redemocratização política e social tornou-se um divisor de águas, um marco para o ensino de História na contemporaneidade, sobretudo pelo abandono de antigas concepções teórico-metodológicas e pela valorização do papel a ser desempenhado pelo professor nos processos de reforma educacional, dada a consideração da escola e de seus sujeitos como produtores da "cultura escolar".

Mesmo em face das ações conservadoras contrarreformistas, parte das inovações trazidas pelo debate na década de 1980 esteve presente nas legislações relativas ao ensino de História durante toda a década de 1990, como no caso dos Parâmetros Curriculares Nacionais (PCN), que até os dias atuais permeiam as discussões acerca do ensino de História nos planos curriculares e livros didáticos. Também há no texto de introdução do novo currículo de História do São Paulo faz escola uma referência à continuação do debate iniciado pela Cenp em 1986.

A recuperação do processo de formulação do currículo para a disciplina de História na década de 1980, por mais difícil e carregada de tensões que tenha sido, explicita certa efervescência de ideias e contributos de diferentes agentes, para além do Estado. Mas como foi o processo de elaboração e implementação do atual currículo São Paulo faz escola, vigente desde 2008? Quais conflitos e tensões podem ser identificados nesse processo? As respostas a tais questões 
serão buscadas por meio da análise de duas dimensões curriculares: a discursiva e a prática, representadas, respectivamente, pelos documentos da reforma curricular elaborados pela SEE-SP e pelos depoimentos dos sujeitos educacionais (professores de História e gestores escolares) acerca de suas experiências nesse processo.

\section{ElaboraÇÃo E IMPlEMENTAÇÃo do CURRÍCUlo DE HistóRIA NO SÃo PAULO FAZ ESCOLA: PARTICIPAÇÃO?}

Em busca de reverter os sucessivos baixos desempenhos obtidos pelos alunos da rede estadual nas recentes avaliações de rendimento escolar estadual e nacional, a SEE-SP, em agosto de 2007, definiu o caminho que conduziria a educação rumo à melhoria da qualidade. Lançado pelo ex-governador José Serra e pela então secretária da educação Maria Helena Guimarães de Castro, o plano de metas e ações São Paulo: uma nova agenda para a educação pública anunciava mudanças estruturais abrangentes para a rede de ensino (São Paulo, 2007).

Com foco na uniformização curricular das escolas públicas e no desenvolvimento das competências leitora e escritora em todos os níveis de ensino, a SEE-SP almejava subsidiar os alunos da rede para um melhor desempenho nos exames externos. Mais especificamente em relação às mudanças previstas para "Currículo e expectativas de aprendizagem", a SEE-SP preconizou:

1. Divulgação das propostas curriculares e expectativas de aprendizagem para todas as séries e disciplinas do Ensino Fundamental e Médio em setembro de 2007; 2. Consulta à rede e capacitação dos professores de outubro a dezembro de 2007, com a utilização da estrutura da Rede do Saber; 3. Implantação das orientações curriculares no planejamento pedagógico de fevereiro de 2008. (São Paulo, 2007)

A par de tais proposições, a SEE-SP, de acordo com a Resolução no 92 de 2007 - que dispõe sobre a reorganização curricular dos ensinos fundamental e médio no estado - iniciou, em 2008, o processo de implementação de propostas curriculares para todas as disciplinas do ensino fundamental II e médio públicos. Na introdução do novo documento curricular verificam-se os novos desígnios educacionais do estado: 
Articulando conhecimento e herança pedagógicos, a Secretaria pretende que esta iniciativa seja, mais do que uma nova declaração de intenções, o início de uma contínua produção e divulgação de subsídios que indicam diretamente na organização da escola como um todo e nas aulas. Ao iniciar esse processo, a Secretaria procura também cumprir seu dever de garantir a todos uma base comum de conhecimentos e competências, para que nossas escolas funcionem de fato como uma rede. (São Paulo, 2008, p.8)

A fim de garantir essa base comum de conhecimentos, ineditamente no cenário educacional paulista, a SEE-SP vem distribuindo bimestralmente nas escolas da rede, concomitantemente aos novos currículos, materiais didáticos próprios que contemplam todas as disciplinas. Trata-se dos Cadernos do Professor e dos Cadernos do Aluno, cuja produção, ao lado das novas matrizes, é mais uma vez assinada por equipes de intelectuais organizadas pela Cenp, agora com apoio da Fundação para o Desenvolvimento da Educação (FDE). Tais materiais abrangem de maneira padronizada todo o desenvolvimento da sequência didática a ser executada pelos professores e alunos da rede pública do estado.

Os Cadernos do Professor de História organizam-se em Situações de Aprendizagem que contemplam o conteúdo disciplinar de todo o ano letivo. O material indica aos docentes como e em quanto tempo tais situações devem ser executadas. Propõe formas de sondagem e sensibilização dos alunos em relação aos assuntos a serem tratados na aula. Além disso, aponta quais competências e habilidades devem ser desenvolvidas com as atividades propostas, indicando metodologias, recursos materiais e estratégias para desenvolvê-las. Finalmente, o Caderno sugere formas de avaliação e de recuperação acerca dos conteúdos trabalhados.

Por sua vez, os Cadernos do Aluno de História, à semelhança do material didático do professor, também se organizam em Situações de Aprendizagem. Esses apostilados apresentam-se como uma compilação de exercícios, além de também sugerirem direcionamentos para que os alunos possam aprofundar seus conhecimentos de maneira autônoma. Em geral, os Cadernos do Aluno de História trazem as Situações de Aprendizagem divididas em seções, a saber: "Leitura e Análise de Texto", "Pesquisa Individual”, "Pesquisa em Grupos”, "Lição de Casa", "Você sabia?", "Para saber mais" e "Você aprendeu?" e, ao término de cada Situação, "O que eu aprendi...”. 
Vale ressaltar que ao longo do processo de implementação dos novos currículos nas escolas da rede pública paulista, a SEE-SP lançou dois documentos curriculares para a disciplina de História, os quais apresentam basicamente a mesma formatação: o primeiro é a proposta curricular divulgada pela Secretaria paulista em 2008 e o segundo é uma nova versão da proposta feita pela Secretaria após diálogos estabelecidos com os profissionais da rede no intuito de melhorar o primeiro documento. Contudo há discordâncias entre a SEE-SP e os sujeitos educacionais acerca desses diálogos.

De acordo com o plano de metas e ações de 2007, São Paulo: uma nova agenda para a educação pública, mais especificamente referente às mudanças previstas para "Currículo e expectativas de aprendizagem", a reestruturação curricular deveria se processar na rede estadual de ensino de acordo com as seguintes etapas:

1. Divulgação das propostas curriculares e expectativas de aprendizagem para todas as séries e disciplinas do Ensino Fundamental e Médio em setembro de 2007; 2. Consulta à rede e capacitação dos professores de outubro a dezembro de 2007, com a utilização da estrutura da Rede do Saber; 3. Implantação das orientações curriculares no planejamento pedagógico de fevereiro de 2008. (São Paulo, 2007)

De maneira semelhante à elaboração das três primeiras versões curriculares da disciplina de História pela Cenp nos anos 1980, tais etapas pressupunham a postura ativa que os profissionais da educação da rede deveriam ter no processo de elaboração das novas matrizes curriculares. Assim, no ambiente virtual da Rede do Saber, os professores seriam consultados em 2007 para auxiliar na elaboração dos novos currículos. Caberia a eles a função de informar à Secretaria as "boas" experiências de ensino-aprendizagem que possuíam, ao acessar o ambiente virtual e atender às seguintes orientações:

Para participar, basta preencher o formulário que será ponto de partida do nosso trabalho. A divulgação, sistematização, análise e revisão das iniciativas já existentes permitirão compor o mapa real da nossa rede. Será ele a apontar uma proposta de currículo para o Estado, com a participação de todos e voltada para um aprendizado mais efetivo. Uma rede com identidade própria, em benefício de nossos alunos. 
Desse modo, para a SEE-SP, a construção dos novos currículos e de seus materiais didáticos foi um processo democrático, que considerou as discussões educacionais anteriores, contando com a participação de professores e gestores da rede. Na introdução da proposta curricular de 2008, a Secretaria observou que a reforma curricular partiu dos "conhecimentos e das experiências práticas já acumuladas, ou seja, da sistematização, revisão e recuperação de documentos, publicações e diagnósticos já existentes e do levantamento e análise dos resultados de projetos ou iniciativas realizadas" (São Paulo, 2008, p.8). A participação da rede no processo de reforma curricular foi mais uma vez referenciada no currículo em 2010.

Entretanto, apesar de amplamente divulgado pela SEE-SP como um movimento democrático, com ampla participação do magistério paulista, os depoimentos dos sujeitos educacionais entrevistados revelam que a consulta eletrônica aos professores da rede parece não ter sido tão incisiva quanto divulga a Secretaria, o que revela um aspecto de discordância entre os dois discursos. Um dos professores de História entrevistado não se recorda de ter sido chamado para participar da elaboração dos novos currículos. Para ele, tratou-se de uma imposição do poder público:

Então, em 2008, eu lembro que no início do ano eles publicaram a proposta curricular que, no meu ponto de vista, na verdade não foi uma proposta, foi uma imposta, por que ela já veio pronta. Se você for à Secretaria da Educação, eles podem falar: "Não, mas houve uma discussão no Estado". Eu não participei dessa discussão.

De maneira semelhante, uma das Professoras Coordenadoras (PC) revela em seu depoimento que o primeiro e maior problema enfrentado pela SEE-SP durante a reforma curricular não esteve ligado à qualidade dos materiais didáticos distribuídos, tampouco às concepções seguidas pelos novos currículos, mas ao fato de se constituir como uma prescrição do poder público: "Embora tivesse o nome de proposta, nós sabíamos que tínhamos que fazer”. Para essa profissional,

num primeiro momento, para muita gente, representou uma imposição. E isso, eu acho, afastou algumas pessoas, alguns quiseram até rejeitar a proposta. Não significa que a proposta não tenha suas coisas boas, porque não tem como reconhecer 
que não é importante um currículo unificado para o Estado ... Então, num primeiro momento, o trabalho foi difícil, porque a proposta chegou, mas sem antes ter havido uma discussão. O que não se caracteriza como uma coisa ruim, uma coisa nociva para o trabalho, não é isso. Eu acho que a rejeição se deu mais pela forma como foi implementado.

De acordo com as proposições trazidas pelos teóricos da "cultura escolar" (Chervel, 1991; Forquin, 1993; Julia, 2001), os quais confirmam a capacidade que a escola possui de edificar uma cultura particular mediante a "confecção" de seus produtos, quando não há participação efetiva dos sujeitos educacionais no processo de reforma - seja ela curricular ou não - é gerado um sentimento de imposição e uma consequente atitude de resistência e recusa, já que as propostas feitas unilateralmente pelo poder público não levam em conta a experiência de cada escola e, por esse motivo, se mostram ineficazes na solução de seus problemas. Gusmão (2004) observa que tal posicionamento do poder público leva ao "alheamento" os profissionais da Educação.

Tal forma de compreender o início da reforma curricular foi a mesma das associações de professores do estado de São Paulo. Para os órgãos representantes do magistério, tratou-se de uma ação "alinhada com as diretrizes sociais e econômicas do chamado capitalismo globalizado que, frente à atual crise mundial, demonstra não responder às necessidades da sociedade”. Maria Cecília Mello Sarno, presidente do Sindicato de Supervisores de Ensino do Magistério no Estado de São Paulo (Apase), acusou "a secretária de Educação, Maria Helena Guimarães de Castro, de adotar uma 'atitude autoritária' e 'intempestiva' por não ouvir os professores". ${ }^{2}$

Naquele momento, a posição dos sindicatos foi reiterada pelas recorrentes greves ocorridas na rede pública de ensino, o que leva a entender que uma parcela dos professores paulistas também partilhou da opinião das associações. Boim relembra o ato público de professores na Praça da República, em 2008. Naquela ocasião, os Cadernos do Professor foram queimados, tal como o "Verdão" nas manifestações do professorado paulista durante os anos 1980. Conforme o autor, "em um ato público, na frente da SEE-SP, em 4 de abril de 2008, um grupo de professores queimou as apostilas em protesto ao novo modelo de ensino adotado em São Paulo" (Boim, 2010, p.36).

De fato, quem pensa o ensino em São Paulo não é exatamente quem o põe em prática, o que é ratificado quando se analisa a equipe que elaborou os novos 
currículos e os Cadernos, a qual não contou com a participação direta dos professores de História da rede. De acordo com os pesquisadores do GT de ensino da Anpuh, os elaboradores do currículo de História no São Paulo faz escola

possuem trajetórias intelectuais consolidadas, e a equipe de professores dos diferentes componentes curriculares apresenta formação nas melhores universidades do país, embora não se tenha verificado preocupação em selecionar profissionais que agreguem em sua formação as interfaces entre conhecimentos acadêmicos e escolares: dedicação à história das disciplinas e dos currículos escolares, ou das didáticas e das práticas e metodologias específicas de ensino-aprendizagem, por exemplo. Ademais, permanece ainda a lógica de elaboração dos currículos sem a participação efetiva dos professores do ensino fundamental e médio, a não ser como executores. (Ciampi et al., 2009, p.362)

De maneira semelhante à produção das $4^{\mathrm{a}}$ e $5^{\mathrm{a}}$ versões do currículo de História da Cenp, esvaziadas da participação dos professores da rede, parece que de certa forma os sujeitos educacionais também foram alijados da construção das novas matrizes no São Paulo faz escola. Tal situação é ainda consubstanciada pela distribuição de materiais didáticos padronizados em toda a rede de ensino. Essa atuação da Secretaria leva ao entendimento de que o novo currículo de História foi visto pelos sujeitos educacionais como "guias curriculares", arquétipo diretor que prescreve todos os passos do processo de ensino-aprendizagem aos docentes, contrapondo dessa maneira o discurso da SEE-SP que o concebeu como uma "proposta curricular", a ser melhorada a partir das experiências do magistério paulista.

Além disso, quando se verifica que em 2008, as Orientações Técnicas (OTs), ocasiões em que o professor recebia capacitação, foram suspensas no estado de São Paulo, chega-se à conclusão de que eles também acabaram sendo expropriados do direito ao debate, ou seja, da possibilidade de se inteirar sobre a reforma curricular, criticá-la ou mesmo de propor alternativas nos encontros com representantes da Diretoria de Ensino (DE) ou da SEE-SP.

Entretanto, durante o planejamento inicial de 2008, os sujeitos educacionais receberam apenas um curso intensivo de capacitação em suas respectivas escolas, com duração de três dias. Nessa ocasião, corpo docente e gestão assistiram às videoconferências em que a SEE-SP apresentou o programa São Paulo 
faz escola, o currículo e os Cadernos de cada disciplina. Tais vídeos não ofereciam, contudo, qualquer oportunidade de participação na reforma curricular, além de sua execução. Tudo já estava pronto, bastava ser posto em prática.

Destacou-se, sobretudo, nesta curta formação dada aos professores, os deveres de cada um com as metas estabelecidas pelo governo paulista. Dessa maneira, o professor foi excluído das discussões pedagógicas que o envolvem, e incapacitado de elaborar o próprio planejamento pedagógico para o ano letivo que começaria em breve, o que evidencia, no novo currículo paulista, uma forte tendência no controle sobre o que e como ensinar. (Boim, 2010, p.14)

Mesmo frente a inúmeras pressões, sobretudo das associações sindicais, também em 2009 e 2010, o estado sustentou a reforma curricular e a distribuição dos materiais didáticos, bem como a postura de não oferecer OTs ao magistério paulista. Ficaram responsáveis por essa tarefa os gestores escolares. Um dos professores de História participantes da pesquisa relembra a chegada dos materiais concomitantemente à suspensão das OTs e questiona a qualidade da orientação oferecida pelo Professor Coordenador (PC) nas diversas disciplinas:

Não teve um trabalho anterior, a Proposta já foi colocada em prática logo de cara e os coordenadores é que tiveram orientação, sempre eles têm orientação. Agora, nós professores, eu me lembro que nós não tivemos capacitações, até porque naquele ano, o Governo daquele período praticamente acabou com as orientações técnicas. O professor não podia sair da sala de aula, aí o coordenador é que teria que dar essas orientações. Mas tem uma coisa, cada coordenador tem a sua disciplina, então como é que ele poderia orientar? Foi uma coisa mais no geral, não específica para cada disciplina.

De acordo com os novos direcionamentos educacionais do estado de São Paulo, em 2008, somente os Professores Coordenadores Orientadores de Disciplina (PCOPs) e supervisores que atuam nas Diretorias de Ensino foram chamados a receber orientação por parte da SEE-SP, contudo, na visão da PCOP de História, isso aconteceu tardiamente:

Nós só tivemos orientação mesmo em Serra Negra no final de agosto, quer dizer, já tinham se passado mais de dois bimestres. Nós tivemos essa orientação ofere- 
cida pelos especialistas dos Cadernos. Aí conseguimos entender toda a lógica do currículo, conseguimos entender a nossa disciplina, a disciplina de História, como que ela estava feita, como foram feitos os recortes para estar trabalhando aqueles temas conceituais e o porquê. Então, a gente foi oferecer uma orientação ao professor, mas não conseguimos chamá-lo. Chegou 2009, ainda não podia chamá-lo, então o atendimento foi mais em $\mathrm{HTPC}^{3}$ e particular, individual. Eu ia à escola e atendia um por um. Então, isso dificultou muito, atravancou muito.

Assim, diferentemente das intencionalidades da SEE-SP, os sujeitos educacionais observaram a reforma curricular como uma iniciativa verticalizada, que não valorizou a prática profissional dos sujeitos e as condições particulares de cada instituição de ensino. Somente em 2011, quarto ano da implementação dos novos currículos e Cadernos, as Diretorias de Ensino convocaram os professores para participarem de uma reunião organizada por áreas de conhecimento, a fim de discutir assuntos relativos à reforma. A PCOP de História, uma das organizadoras do encontro na Diretoria em questão, informou que se tratava de uma reunião para orientação bimestral dos professores da rede acerca das novas matrizes e materiais: "Então, esse primeiro HTPC, que era para acontecer todos os bimestres, mas, pelo jeito, até agora não foi proposto ainda... Mas, no primeiro, a gente sentou com o professor da disciplina, da área. Aliás, colocamos para ele o currículo da área, qual era o objetivo, passo a passo. Estudamos e discutimos o que era, qual era a proposta”.

Resta investigar se nessa ocasião a SEE-SP proporcionou a participação dos sujeitos educacionais no processo de reforma iniciado em 2008, para contornar o "alheamento" do profissional docente e, por conseguinte, os sentimentos de recusa e resistência.

\section{O "HTPC REGIONAL": O DEBATE MORREU?}

Com intuito de promover uma leitura coletiva e interativa do currículo, ministrada pelos PCOPs da área de Ciências Humanas, aconteceu em abril de 2011 um "HTPC regional" na Diretoria de Ensino da cidade em que a pesquisa foi desenvolvida. Nessa reunião, todos os professores das Humanidades foram convocados e arcariam com os custos de suas ausências caso não comparecessem. 
Por isso, as escolas da referida DE transferiram suas atividades normais do HTPC semanal para esse encontro.

Em observação a esse acontecimento, percebeu-se que, apesar de seu caráter obrigatório, alguns docentes mostraram-se bastante entusiasmados com as discussões levantadas, expondo seus pontos de vista, comentando a realidade de suas escolas, apresentando exemplos provenientes de sua prática profissional. Outros, entretanto, pareciam estar ali meramente para "cumprir tabela”, preocupando-se principalmente com o passar das horas.

A intenção do encontro foi promover, entre os responsáveis pelas disciplinas de Ciências Humanas e História, a troca das experiências com o trabalho desenvolvido a partir do material pedagógico em questão. Os professores, divididos em grupos e com o currículo de suas respectivas disciplinas em mãos, dividiram o texto de introdução aos currículos da área de Ciências Humanas e suas Tecnologias do Estado de São Paulo para leitura e apresentação.

Assim, observaram-se discussões acerca da necessidade de adequar o ensino público à nova "sociedade do conhecimento" e ao crescente desenvolvimento das tecnologias do mundo produtivo e questões relativas à preparação dos alunos da rede para a continuação dos estudos em nível superior. Surgiram ainda questionamentos acerca da infraestrutura necessária nas escolas para adentrar o novo mundo tecnológico proposto pelas matrizes curriculares da SEE-SP, já que os professores julgaram que os recursos tecnológicos das instituições de ensino da rede pública, apesar de já disponíveis, eram insuficientes para atender à crescente demanda das salas de aulas.

As críticas dos professores aos materiais didáticos de História disponibilizados pela SEE-SP (Cadernos do Professor e Cadernos do Aluno) foram o que mais chamou a atenção durante esse "HTPC regional". Para os docentes de História, o maior problema verificado no material era a falta de conteúdo disciplinar, mais precisamente a falta de textos expositivos e conceituais sobre os períodos relativos às Situações de Aprendizagem. Os professores ainda criticaram o atraso na chegada dos Cadernos e a extensão das Situações de Aprendizagem propostas pela Secretaria, as quais nem sempre podiam ser cumpridas integralmente durante o ano letivo por razões diversas, como indisciplina e desinteresse dos alunos. 
Frente a tais críticas, o discurso da PCOP de História limitou-se à afirmação de que o atual currículo faz parte dos "novos tempos" sociais e educacionais, ou seja, trata-se de um currículo do tempo presente, da nova sociedade produtiva e tecnológica. Dessa maneira, a profissional preocupou-se em fazer os professores refletirem sobre as atitudes dos alunos desse "novo tempo", ressaltando a necessidade de que sejam também iniciadas algumas mudanças nas tradicionais formas de "ensinar História", ou seja, na prática docente.

Contrariando o entendimento de alguns professores, a PCOP ainda enfatizou que as atividades contidas nos Cadernos não precisariam necessariamente ser cumpridas integralmente, já que, segundo seu ponto de vista, se configuram como sugestões de trabalho para subsidiar o professor no desenvolvimento de temas e assuntos do currículo. Com isso sugeriu aos docentes que outros materiais didáticos poderiam ser empregados no processo de ensino-aprendizagem, dependendo de demandas individuais e contextuais.

Dessa forma, o termo "obrigatoriedade" não esteve presente na fala da PCOP de História, que se preocupou mais com o conceito de "construção". Para ela, implementar o novo currículo de História seria uma construção que cada profissional faria dependendo de seu cotidiano. Entretanto, segundo suas orientações, o professor não poderia deixar em segundo plano o desenvolvimento das competências e habilidades propostas pelo estado de São Paulo para cada ano escolar, já que, segundo seu ponto de vista, isso é o currículo a ser implantado nas escolas públicas paulistas.

Em síntese, pode-se afirmar que, apesar de esse "HTPC regional" ter se configurado como um importante espaço para que os professores pudessem expor suas opiniões sobre o currículo e seus materiais didáticos, os termos "discussão" e "debate" devem ser utilizados com cautela quando se intenciona caracterizar o perfil desse encontro, pois parece ter havido por parte dos docentes mais preocupação em apresentar as agruras de uma jornada de trabalho extenuante e as condições desfavoráveis das escolas onde lecionam, do que em discutir as perspectivas teóricas, metodológicas e práticas do trabalho com o novo currículo paulista e com seus materiais didáticos.

Por sua vez, também o posicionamento adotado pelos PCOPs da área de Ciências Humanas não foi o de elaborar críticas à matriz curricular e aos materiais didáticos, tampouco o de propor alternativas de trabalho com as 
atividades dos Cadernos frente às dificuldades relatadas pelos professores que estavam presentes. Ao contrário disso, a intenção foi tão somente apresentar os materiais didáticos e a matriz curricular já utilizados na rede de ensino desde 2008. Nesse sentido pode-se afirmar que o debate ficou em segundo plano no encontro promovido por esta Diretoria de Ensino.

Após mais de uma hora de discussões, o HTPC foi encerrado com a promessa de que outras reuniões para a troca de experiências e orientação ocorreriam, proposta pela SEE-SP em parceria com as DEs, o que não ocorreu. Um dos professores de História participantes da pesquisa relembra com descrédito a iniciativa da Diretoria de Ensino, atestando até mesmo o caráter reprodutivo do material relacionado a esse encontro:

No primeiro bimestre, nós tivemos uma orientação técnica dada pelo PCOP de História referente ao Caderno 01. Na época, foi uma reunião com todos os professores de História da Diretoria para colocar suas experiências, o que está trabalhando, o que foi ou não trabalhado. Aí, haveria uma no $2^{\circ}$ bimestre e não houve. Não sei o que aconteceu, porque a PCOP, na época, falou que iria chamar novamente para essa reunião, mas não chamou. A reunião teve a coordenação do PCOP e foi feita uma leitura da proposta de História. Eles pediram para fazer uma leitura, fazer um comentário do texto da proposta curricular e ficou apenas nisso, nessa orientação.

Finalmente, o destino tomado por esse "HTPC regional", proposto pela SEE-SP sob a batuta de seus PCOPs, faz lembrar as proposições de Cordeiro acerca das atuais discussões sobre o ensino de História, para quem elas parecem amortecidas, abandonadas se comparadas aos acirrados debates estabelecidos entre diversos atores sociais nos anos 1980. Para esse autor, "pode-se constatar uma espécie de amortecimento do debate: o ensino de História saiu de cena, não representando hoje o mesmo papel que antes, quando parecia para os envolvidos naquelas propostas que, com base na mudança das práticas configuradas no chamado 'ensino tradicional', tanto a escola quanto a própria vida na sociedade seriam radicalmente alteradas" (Cordeiro, 2000).

Restam, portanto, as indagações sobre os motivos que levaram ao abandono do debate que, na década de 1980, representou um avanço para a História como disciplina escolar. 


\section{Conclusẽo}

Ao final deste artigo, ratifica-se a necessidade de uma efetiva participação dos professores no processo da reforma educacional, para que seja evitado o "alheamento" docente frente às imposições do poder público educacional e para que os currículos estejam mais próximos da realidade de cada profissional em seu contexto de trabalho, dada a existência de uma "cultura escolar" inerente a cada instituição em particular.

Nesse sentido, as ações educacionais deveriam endereçar-se para o cotidiano escolar, a fim de responder à crise educacional emergente na contemporaneidade. Se desde o princípio, os projetos de reforma contassem com a participação daqueles que os colocam em prática - professores e gestores -, estariam findos no processo de implantação sentimentos que se relacionam a descrédito, estranhamento e recusa, tão comuns nos processos reformistas feitos verticalmente, sem que a voz dos sujeitos seja considerada.

Como sugere Forquin, para combater a crise é necessário que as propostas curriculares, não somente a de História, contemplem de maneira "universal" tanto as demandas de formação humanitária, social e local, quanto a transmissão de saberes para a resolução das incógnitas contemporâneas, fazendo desaparecer o que se denomina "estrangeiros" e "desenraizados" sociais, concebidos em processos de ensino-aprendizagem que contemplam apenas aspectos da cultura dos grupos dominantes. Tais proposições, entretanto, parecem não ter sido privilegiadas na reforma curricular empreendida pelo estado de São Paulo, tanto no que se refere à elaboração das matrizes e Cadernos quanto no que concerne à forma como foram implementados na rede (Forquin, 1993).

Contudo, os desdobramentos das atuais decisões da SEE-SP na qualidade educacional paulista não podem ser enumeradas agora, uma vez que a reforma continua e passa por constantes alterações, mesmo após a alternância de três secretários educacionais. Identificar e analisar com mais profundidade as implicações do currículo São Paulo faz escola para a educação e para o ensino de História são ações que requerem a realização de outras pesquisas como esta, que buscou contribuir com reflexões sobre as duas últimas reformas curriculares paulistas para a disciplina de História. 


\section{REFERÊNCIAS}

BITTENCOURT, Circe. Capitalismo e cidadania nas atuais propostas curriculares de História. In: . (Org.) O saber histórico na sala de aula. 3.ed. São Paulo: Contexto, 1998.

BOIM, Thiago Figueira. O que e como ensinar: proposta curricular, materiais didáticos e prática de ensino nas escolas públicas estaduais em São Paulo (2008-2009). 2010. Dissertação (Mestrado em Educação: História, Política, Sociedade) - Pontifícia Universidade Católica de São Paulo. São Paulo, 2010.

CHERVEL, André. Historia de las disciplinas escolares: reflexiones sobre un campo de investigación. Revista de Educación, n.295, p.59-111, 1991.

CIAMPI, Helenice et al. O currículo bandeirante: a Proposta Curricular de História no Estado de São Paulo, 2008. Revista Brasileira de História, São Paulo, v.29, n.52, p.361-382, 2009.

CORDEIRO, Jaime Francisco. A História no centro do debate: as propostas de renovação do ensino de História nas décadas de setenta e oitenta. São Paulo: Cultura Acadêmica, 2000. (Coleção Pedagogia).

FAGNANI, Eduardo. Política Social e pactos conservadores no Brasil: 1964-1992. Cadernos Fundap, p.59-102, set.-dez. 1996.

FONSECA, Selva Guimarães. Caminhos da História ensinada. 9.ed. Campinas (SP): Papirus, 2006.

FORQUIN, Jean Claude. Escola e cultura: as bases sociais e epistemológicas do conhecimento escolar. Trad. Guacira Lopes Louro. Porto Alegre: Artes Médicas Sul, 1993.

GUSMÃO, Emery Marques. Memórias de quem ensina história: cultura e identidade docente. São Paulo: Unesp, 2004.

JULIA, Dominique. A cultura escolar como objeto histórico. Trad. Gizele de Souza. Revista Brasileira de História da Educação, n.1, p.9-43, jan.-jun. 2001.

MARTINS, Maria do Carmo. A Cenp e a criação do currículo de História: a descontinuidade de um projeto educacional. Revista Brasileira de História, São Paulo, v.18, n.36, p.39-60, 1998.

A construção da proposta curricular da Cenp no período de 1986 a 1992: confrontos e conflitos. Dissertação (Mestrado em Educação: Metodologia de Ensino) - Faculdade de Educação, Universidade Estadual de Campinas. Campinas (SP), 1996.

SÃO PAULO (Estado). Currículo do Estado de São Paulo: Ciências Humanas e suas tecnologias. São Paulo: SEE, 2010.

. Proposta Curricular do Estado de São Paulo: História. São Paulo: SEE, 2008. 
SÃO PAULO (Estado). Secretaria da Educação. São Paulo, uma nova agenda para a Educação Pública. São Paulo, 2007.

SARMENTO, Manuel Jacinto. O estudo de caso etnográfico em educação. In: ZAGO, Nadir; CARVALHO, Marília; VILELA, Rita (Org.) Itinerários de pesquisa. Rio de Janeiro: DP\&A, 2003.

SILVA JUNIOR, João dos Reis; FERRETI, Celso João. O institucional, a organização e a cultura da escola. São Paulo: Xamã, 2004.

\section{NOTAS}

${ }^{1}$ Financiamento da Fundação de Amparo à Pesquisa do Estado de São Paulo (Fapesp).

${ }^{2}$ Disponível em: www.cnte.org.br/index2.php?option=com_content\&dopdf=1\&id=1596; Acesso em: 13 abr. 2012.

${ }^{3}$ Hora de Trabalho Pedagógico Coletivo (HTPC) realizada semanalmente por todas as escolas da rede paulista. Desde 2012, o termo HTPC foi substituído por Aula de Trabalho Pedagógico Coletivo (ATPC), pois houve redução no tempo de trabalho que antes era de 60 minutos e agora é de 50 minutos, ou seja, uma hora aula.

Artigo recebido em setembro de 2013. Aprovado em outubro de 2013. 